\title{
Migrant workers
}

31 OCCUPATIONAL RISKS AMONG IMMIGRANT WORKERS IN EUROPE COMPARED TO AUTOCHTHONOUS WORKERS

Fernando G Benavides, ${ }^{1}$ Elena Ronda, ${ }^{1}$ Emily Felt, ${ }^{1}$ Katia Levecque, ${ }^{2}$ John G Love, ${ }^{3}$ Ronan Van Rossem ${ }^{1} \mathrm{C} / \mathrm{SAL}$, Barcelona, Spain; ${ }^{2}$ Ghent University, Ghent, Belgium;

${ }^{3}$ Robert Gordon University, Aberdeen, UK

10.1136/oemed-2011-100382.31

Objectives The global increase in geographical mobility among workers has translated into a major demographic change in Europe. Migratory flows have taken place primarily in response to the labour demand of expanding national economies. However, the entry into the labour force has not been easy for migrants. We aim to compare the prevalence of six occupational risk factors among immigrants and autochthonous workers in Europe.

Methods Data used comes from the European Working Condition Survey (EWCS-2005, n=29 654 workers from 31 European countries). We examined differential prevalence rates in immigrant and autochthonous workers of: working $>5$ days/week, regular shift-working, repetitive hand/arm movements, exposure to noise (need to raise voice to talk to people), working in tiring/painful positions and working at very high speeds. Exposure was considered to be those reporting working in each condition almost/all of their working-time. Immigrant was defined as a person without citizenship of the country where the interviews were conducted. Prevalence ratios were adjusted for age, gender and education (adjusted-PR).

Results Four of the occupational risks examined were found to be associated with immigration status: repetitive movements (adjusted-PR $=1.4 ; 95 \%$ CI 1.2 to 1.5 ), noise-exposure $(1.5 ; 1.3$ to 1.8$)$, working in tiring/painful positions $(1.4 ; 1.2$ to 1.6) and very high speeds (1.5; 1.2 to 1.6$)$; the exceptions: shift working and working $>5$ days/week.

Conclusions Immigrant workers in Europe are faced with additional occupational risks compared to autochthonous workers. Notwithstanding the limitations of the dataset in regards to the low sample size of the migrant group, the findings suggest that special attention must be paid to their working conditions. 